\title{
Trends in direct normal irradiance in Oregon: Comparison of surface measurements and ISCCP-derived irradiance
}

\author{
Sina Lohmann, ${ }^{1}$ Laura Riihimaki, ${ }^{2}$ Frank Vignola, ${ }^{2}$ and Richard Meyer ${ }^{1}$ \\ Received 7 August 2006; revised 11 September 2006; accepted 18 October 2006; published 19 January 2007.
}

[1] Long-term pyrheliometer measurements of direct normal irradiance at three sites in Oregon are compared to irradiance calculated from data of the International Satellite Cloud Climatology Project. An increase of direct normal irradiance of up to $1 \mathrm{~W} / \mathrm{m}^{2}$ per year between 1980 and 2004 is found in the measured data. The increase seems to be partially caused by stratospheric aerosols from two major volcano eruptions. After removing data for the years most affected by volcanic aerosol, two of the three sites still show a significant increase in direct normal irradiance, indicating other atmospheric changes may contribute to the observed trends. From 1984-2004, for which satellite data are available, both data sets correlate very well and show an increase in direct normal irradiance of $0.3 \mathrm{~W} / \mathrm{m}^{2}$ per year on average. In both data sets trends vary seasonally. A strong increase is observed during summer and fall. At two sites a significant decrease during winter, which is consistent in measured and satellite derived values, counteracts part of the summer increase. Citation: Lohmann, S., L. Riihimaki, F. Vignola, and R. Meyer (2007), Trends in direct normal irradiance in Oregon: Comparison of surface measurements and ISCCP-derived irradiance, Geophys. Res. Lett., 34, L02705, doi:10.1029/2006GL027322.

\section{Introduction}

[2] Several earlier studies [e.g., Liepert, 2002; Liepert and Tegen, 2002; Gilgen et al., 1998] mainly find a decrease in total irradiance, when analyzing the period between 1960 and 1990. This phenomenon became widely known as "global dimming". However, since 1990 total irradiance seems to be increasing at many measurement sites worldwide [Wild et al., 2005] and also globally as derived from satellite data [Pinker et al., 2005]. Most authors assume that the main cause of the changes in total irradiance is amount and/or composition of aerosol [e.g., Stanhill and Cohen, 2001; Liepert and Tegen, 2002; Alpert et al., 2005]. The highest rates of decrease are found in highly populated areas [Alpert et al., 2005], whereas extinction measurements at very remote sites show no significant trends [Schwartz, 2005]. Since the late 1980s emissions of anthropogenic aerosol in many regions were strongly reduced [Sharma et al., 2004]. Therefore this could be responsible for the observed increase in irradiance since then. However, it should be noted that the observed trends for total irradiance

\footnotetext{
${ }^{1}$ Institute of Atmospheric Physics, Deutsches Zentrum für Luft- und Raumfahrt, Wessling, Germany.

${ }^{2}$ Solar Radiation Monitoring Lab, Department of Physics, University of Oregon, Eugene, Oregon, USA.
}

Copyright 2007 by the American Geophysical Union. 0094-8276/07/2006GL027322\$05.00 are often not significant, as enhanced scattering causes only modest reduction of total irradiance. Analyzing mainly the direct beam component could lead to stronger more significant changes.

[3] Very few time series of surface measurements of direct irradiance are available for the time before 1990 [e.g., Faiman et al., 2004]. In this study, measurements of direct irradiance for three monitoring stations in Oregon are analyzed for the exceptionally long period from 1978 to 2004. They are compared to direct irradiance derived from cloud data from the International Satellite Cloud Climatology Project (ISCCP) [Schiffer and Rossow, 1983]. Trend analyses are carried out for both data sets. The long timeseries present a unique opportunity to study direct irradiance for years before and after the eruptions of Pinatubo in 1991 and El Chichón in 1982. This allows scrutiny of the influence of volcanic aerosols on the derived trends of direct irradiance.

\section{Data Sets and Procedure}

[4] Direct normal irradiance is derived from ISCCP cloud data through radiative transfer calculations according to the method developed by Lohmann et al. [2006]. The ISCCP FD data set [Zhang et al., 2004] used here has a spatial resolution of $280 \mathrm{~km}$ and a temporal resolution of 3 hours. Currently it covers the period from July 1983 to December 2004. Monthly means of aerosol optical depth are gathered from model results of Tegen et al. [1997]. Due to the unavailability of a data set that describes the actual aerosol optical depth for tropospheric aerosols the same annual cycle has to be assumed for all years. At least the stratospheric aerosol optical depth, which varied strongly over time, could be described more realistically according to Sato et al. [1993]. This data set ends in 1999, but as no high reaching volcanic eruption happened in between, an exponential decay is assumed since then. This assumption is well proved by lidar observations, e.g., by Jäger [2005]. The complete DLR-ISIS-method (Irradiance at the Surface derived from ISCCP cloud data) has been validated in an earlier study with irradiance derived from high resolution satellite data averaged over the area of complete ISCCP boxes [Lohmann et al., 2006]. There it is found that DLRISIS on average underestimates direct normal irradiance by $2 \%$.

[5] Data from three stations in Oregon are used for the comparison [Riihimaki and Vignola, 2005], with the earliest measurements starting March 1979 for Burns, December 1977 for Eugene and June 1979 for Hermiston (Figure 1). The station in Hermiston was out of operation from January 1990 to October 1992. At each site direct normal irradiance is measured by an Eppley Normal Incidence Pyrheliometer 


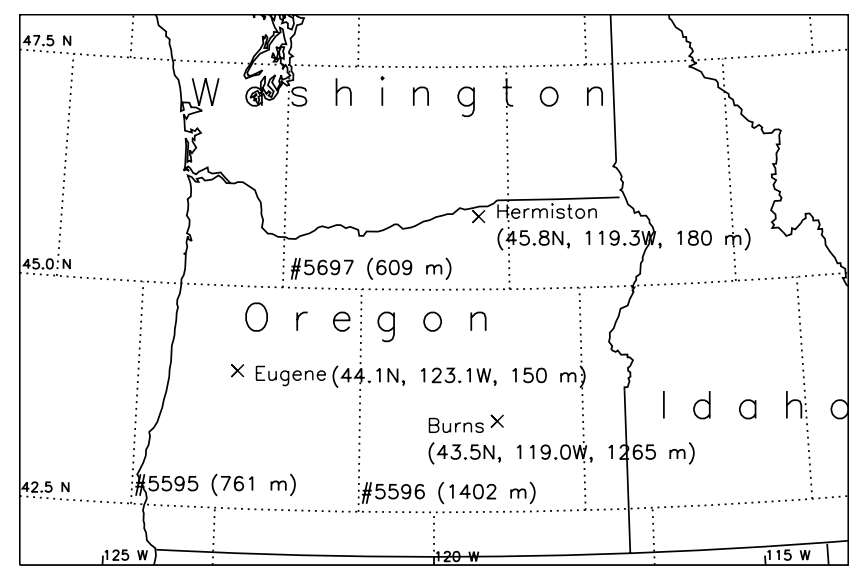

Figure 1. Location of the surface stations in Oregon. Numbers in parentheses are coordinates and elevation above sea level. Dashed lines indicate the ISCCP boxes with box numbers and box-averaged elevation.

with calibrations traceable to the WMO standard. Field calibrations were carried out yearly except for the period from 1987 to 1992 . From calibration with reference instruments at the National Renewable Energy Laboratory and Eppley Laboratory it is assumed that measurements in the field have an absolute 1-sigma accuracy of $\pm 1.5 \%$.

[6] Trends are derived from annual averages for the parallel observation period from 1984 to 2004. In the case of Hermiston the missing months in the surface measurements were also omitted in the satellite derived data. Additionally, seasonal trends are analyzed. To evaluate the influence of volcanic aerosol trends are re-calculated omitting the three years most affected by the eruptions of El Chichón (1982/83/84) and Pinatubo (1991/92/93).

\section{Results and Discussion}

[7] Long-term averages of the surface data and the corresponding DLR-ISIS grid boxes are given in Table 1. There is a large bias between the surface and DLR-ISIS data for the Burns and Hermiston stations. Part of the bias, which on average over all three sites is $-16 \%$, is probably caused by an overestimation of the cloud amount by ISCCP as reported, e.g., by Rossow and Schiffer [1999]. Also, some deviations between the time series have to be expected due to the fact that site-specific measurements are compared to averages gathered over approximately $80000 \mathrm{~km}^{2}$. It is unlikely that the pyrheliometers are placed at sites which are highly representative of the average over the ISCCP boxes. The region under investigation here is partly very mountainous which can cause large spatial variability of the solar irradiance field. This fact can already be seen intercomparing measurements: The distance between the three stations is in the range of the size of a grid box. The differences between measurements at the three sites therefore give an indication of the variability to be expected within the ISCCP boxes in this region. Table 1 shows that these differences are of the same magnitude as the deviations between measurements and the DLR-ISIS data. This indicates that most of the bias could be caused by the fact that the measurements are taken at places which are a little sunnier than the average of the box. To remove the bias, anomalies of annual averages against the long-term average for the overlapping 1984 to 2004 period are analyzed.

[8] Viewing the temporal patterns of the anomalies (Figure 2) show good agreement of surface-and satellitebased observations for all three sites, indicated also by relatively high correlation coefficients for the annual anomalies (Table 1). For Burns the correlation coefficient is 0.87 , showing very similar temporal behavior between the station and the grid box average. For Eugene and Hermiston correlation coefficients are lower $(0.67$ and 0.71$)$. Again, this can be caused by differences between the box average and the measurements at a single station. For example, $15 \%$ of the grid box containing Eugene is covered by ocean (Figure 1).

[9] Both the satellite-derived irradiance and the surface measurements show positive trends for annual averages of direct normal irradiance (Table 2). None of the trends for the time 1984-2004 is significant applying a Student's t-test. The increasing trends for Burns and Eugene result from a strong increase during summer and fall, partially compensated by a decrease during winter (Table 2). For Hermiston direct normal irradiance is increasing for all seasons. The seasonally differing behavior of trends can also be found in the averages for the grid boxes in the DLR-ISIS data set. Exceptions are summer values for the grid box containing Eugene and spring values for the grid box containing Hermiston. Grid box averages indicate a decreasing trend whereas surface measurements are increasing. However, none of these trends is statistically significant. The differences between the trends in the two data sets again could be caused by differing spatial resolutions, but also due to shortcomings of the ISCCP cloud processing method [Rossow and Schiffer, 1999; Wielicki and Parker, 1992]. Nevertheless cloud amounts in the ISCCP data set show no significant change for the three grid boxes between 1984 and 2004. It is assumed that changes of direct irradiance are

Table 1. Long-Term Averages for the Overlapping Time Period 1984-2004, Bias and Root Mean Square Deviations (RMS) Between Measurements and Satellite-Derived Direct Normal Irradiance

\begin{tabular}{|c|c|c|c|c|c|c|c|}
\hline & $\begin{array}{c}\text { Surface average, } \\
\mathrm{W} / \mathrm{m}^{2}\end{array}$ & $\begin{array}{c}\text { DLR-ISIS average, } \\
\mathrm{W} / \mathrm{m}^{2}\end{array}$ & Bias, $\mathrm{W} / \mathrm{m}^{2}$ & Bias, \% & $\begin{array}{c}\text { Correlation } \\
\text { Coefficients } \mathrm{R}^{\mathrm{a}} \\
\end{array}$ & $\begin{array}{l}\mathrm{RMS}, \\
\mathrm{W} / \mathrm{m}^{2}\end{array}$ & RMS, \% \\
\hline Burns & 230 & 182 & 48 & -21 & 0.87 & 49 & 21 \\
\hline Eugene & 158 & 154 & 4 & -3 & 0.67 & 9 & 5 \\
\hline Hermiston & 203 & 152 & 51 & -25 & 0.71 & 51 & 25 \\
\hline Average & 197 & 162 & 34 & -16 & 0.75 & 36 & 17 \\
\hline
\end{tabular}

${ }^{\mathrm{a}}$ Correlation coefficients are for annual anomalies of the data sets. 


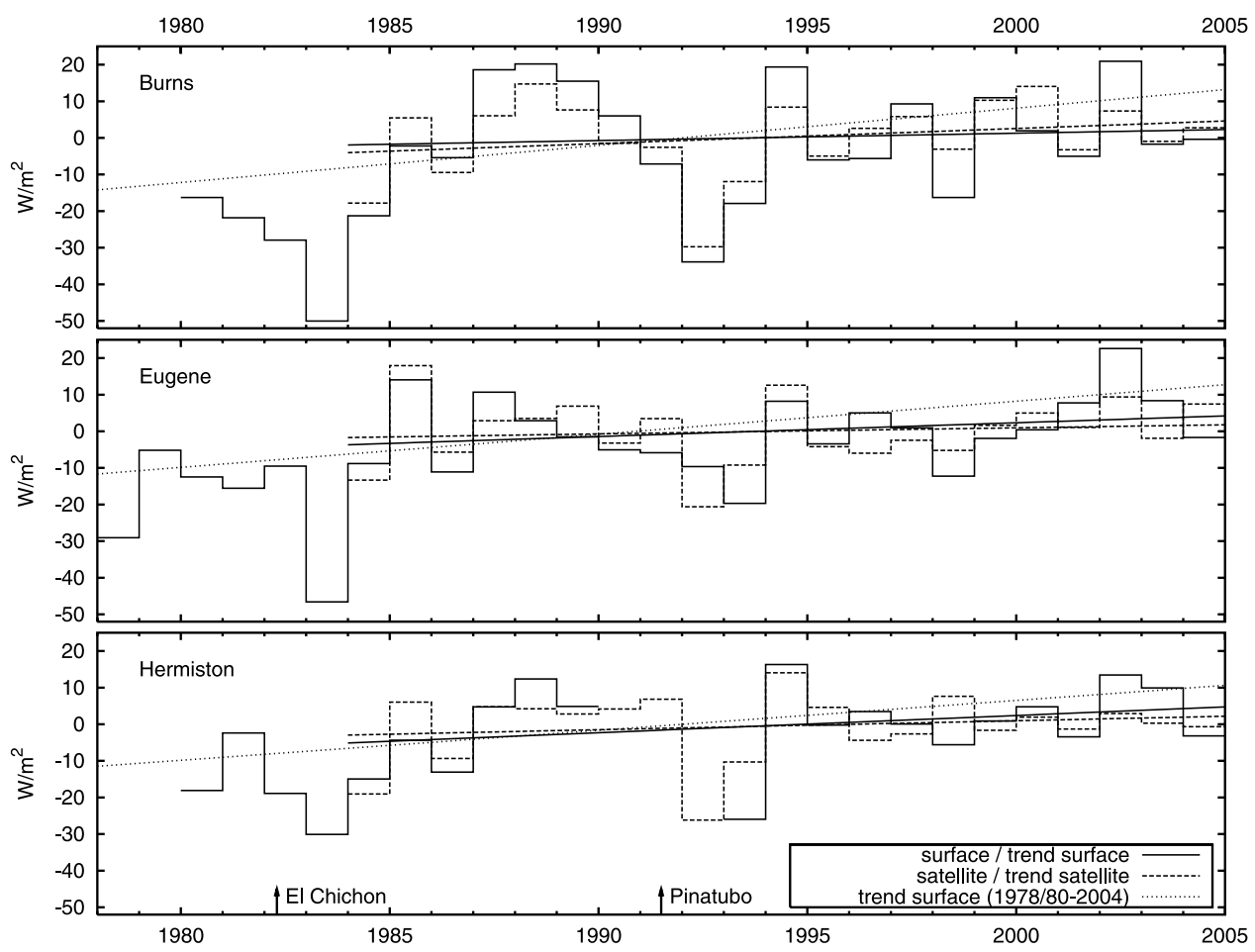

Figure 2. Annual averages of satellite derived irradiance (solid lines) and surface data (dashed lines) as deviations from their 1984-2004 average. Trend lines in the same style as the time series are based on 1984-2004 data, dotted lines are for the complete available surface data.

strongly influenced by the stratospheric aerosol from volcanic eruptions.

[10] Recalculation of the trends omitting the years most affected by the eruptions of El Chichón and Pinatubo resulted in none or slightly decreasing trends in the DLRISIS data (Table 2). This confirms that increasing trends in the DLR-ISIS data are caused by volcanic aerosol. Trends in the surface measurements are weaker and become negative for Burns. Therefore, trends in the surface measurements are strengthened by the stratospheric aerosol, but this does not seem to be the only reason for the increase in direct normal irradiance. Taking into account the full length of the data set from 1980 and 1978 respectively, trends in the surface data become very strong and significant (Table 2). Again, omitting the years affected by the volcanic eruptions weakens the trends, but only for Burns do values drop below the $90 \%$ significance level. The surface data also confirm a strong influence of volcanic eruptions, but trends remain strong when excluding years with strong aerosol loads. Since the cloud data from the ISCCP data set show no

Table 2. Annual and Seasonal Trends of Surface and Satellite Based Direct Normal Irradiance ${ }^{\mathrm{a}}$

\begin{tabular}{|c|c|c|c|c|c|c|}
\hline \multirow[b]{2}{*}{ Season } & \multicolumn{3}{|c|}{ Surface Stations } & \multicolumn{3}{|c|}{ DLR-ISIS Boxes } \\
\hline & Burns & Eugene $^{\mathrm{b}}$ & Hermiston $^{\mathrm{c}}$ & 5596, Burns & 5595, Eugene $^{\mathrm{b}}$ & 5697, Hermiston $^{\mathrm{c}}$ \\
\hline Spring & -0.18 & +0.49 & +0.24 & -0.04 & +0.58 & -0.48 \\
\hline Summer & $+1.21^{\mathrm{d}}$ & +0.80 & +0.91 & $+1.72^{\mathrm{d}}$ & -0.19 & +0.98 \\
\hline Fall & $+1.60^{\mathrm{e}}$ & $+1.31^{\mathrm{d}}$ & $+0.77^{\mathrm{d}}$ & +0.77 & $+1.13^{\mathrm{d}}$ & +0.86 \\
\hline Winter & $-1.28^{\mathrm{e}}$ & $-0.70^{\mathrm{e}}$ & +0.23 & -0.33 & -0.50 & +0.14 \\
\hline \multicolumn{7}{|l|}{ Annual } \\
\hline $1980-2004$ & $+1.01^{\mathrm{e}}$ & $+0.90^{\mathrm{f}}$ & $+0.82^{\mathrm{f}}$ & & & \\
\hline $1984-2004$ & +0.20 & +0.38 & +0.47 & +0.41 & +0.17 & +0.25 \\
\hline \multicolumn{7}{|c|}{ Without volcano years ${ }^{\mathrm{g}}$} \\
\hline $1980-2004$ & +0.37 & $+0.72^{\mathrm{f}}$ & $+0.46^{\mathrm{e}}$ & 0.00 & -0.13 & -0.09 \\
\hline $1985-2004$ & -0.38 & +0.16 & +0.19 & & & \\
\hline
\end{tabular}

${ }^{\mathrm{a}}$ Trends in $\mathrm{W} / \mathrm{m}^{2} / \mathrm{yr}$.

${ }^{\mathrm{b}}$ For Eugene full analysis period starts 1978.

${ }^{c}$ For Hermiston the years missing in the surface measurements $(1990-1992)$ have also been omitted in the satellite data before trend analysis.

${ }^{\mathrm{d}}$ Significant results on a $90 \%$ confidence level according to a student-t-test.

eSignificant results on a $95 \%$ confidence level according to a student-t-test.

${ }^{\mathrm{f}}$ Significant results on a $99 \%$ confidence level according to a student-t-test.

${ }^{\mathrm{g}}$ The last two lines give the trend excluding the years most affected by volcanic aerosol (1982/83/84 and 1991/92/93). 
changes for the three boxes studied here it is assumed that the changes in direct normal irradiance are mostly due to changes in tropospheric aerosol. Tropospheric aerosol in the DLR-ISIS data set is constant throughout the years, therefore variability of irradiance due to changes in aerosol is not covered. But also changes in cloud properties on a smaller scale than an ISCCP grid box could be responsible for the observed changes.

[11] In future studies, beam irradiance will be analyzed for changes of clear sky total optical depth and cloud frequency. Analysis of additional parameters like global irradiance will give further hints into causes of observed changes.

[12] In general the temporal changes in measured and satellite derived data agree well. DLR-ISIS is a global data set, which shows even stronger trends of direct normal irradiance in many other regions [Lohmann et al., 2006]. The intercomparison presented in this paper supports the findings of Lohmann et al. [2006]. But more validation work like this study should be done for other sites, which offer long-term direct normal irradiance data.

[13] Acknowledgments. Many thanks to the station operators and to Bill Rossow and Yuanchong Zhang from NASA GISS for providing the ISCCP FD data set. This research was partly funded by the German Helmholtz Society within the Virtual Institute for Energy Meteorology, NSF GK-12 grant DGE-0231997, the Eugene Water and Electric Board, Bonneville Power Administration, and the Energy Trust of Oregon.

\section{References}

Alpert, P., P. Kishcha, Y. J. Kaufman, and R. Schwarzbard (2005), Global dimming or local dimming?: Effect of urbanization on sunlight availability, Geophys. Res. Lett., 32, L17802, doi:10.1029/2005GL023320.

Faiman, D., D. Feuermann, P. Ibbetson, B. Medwed, A. Zemel, A. Ianetz, V. Liubansky, I. Setter, and S. Suraqui (2004), The Negev radiation survey, J. Sol. Energy Eng., 126, 906-914.

Gilgen, H., M. Wild, and A. Ohmura (1998), Means and trends of shortwave irradiance at the surface estimated from Global Energy Balance Archive Data, J. Clim., 11, 2042-2061.

Jäger, H. (2005), Long-term record of lidar observations of the stratospheric aerosol layer at Garmisch-Partenkirchen, J. Geophys. Res., 110, D08106, doi:10.1029/2004JD005506.

Liepert, B. G. (2002), Observed reductions of surface solar radiation at sites in the United States and worldwide from 1961 to 1990, Geophys. Res. Lett., 29(10), 1421, doi:10.1029/2002GL014910.
Liepert, B., and I. Tegen (2002), Multidecadal solar radiation trends in the United States and Germany and direct tropospheric aerosol forcing, J. Geophys. Res., 107(D12), 4153, doi:10.1029/2001JD000760.

Lohmann, S., C. Schillings, B. Mayer, and R. Meyer (2006), Long-term variability of solar direct and global radiation derived from ISCCP data and comparison with reanalysis data, Sol. Energy, 80, 1390-1401.

Pinker, R. T., B. Zhang, and E. G. Dutton (2005), Do satellites detect trends in surface solar radiation?, Science, 308, 850-854.

Riihimaki, L., and F. Vignola (2005), Trends in direct normal solar irradiance in Oregon from 1979-2003, paper presented at ISES Solar World Congress, Am. Sol. Energy Soc., Orlando, Fla., 6-12 Aug.

Rossow, W. B., and R. A. Schiffer (1999), Advances in understanding clouds from ISCCP, Bull. Am. Meteorol. Soc., 80(11), 2261-2287.

Sato, M., J. E. Hansen, M. P. McCormick, and J. B. Pollack (1993), Stratospheric aerosol optical depths, 1850-1990, J. Geophys. Res., 98(D12), $22,987-22,994$.

Schiffer, R. A., and W. B. Rossow (1983), The International Satellite Cloud Climatology Project (ISCCP): The first project of the World Climate Research Programme, Bull. Am. Meteorol. Soc., 64(7), 779-784.

Schwartz, R. D. (2005), Global dimming: Clear-sky atmospheric transmission from astronomical extinction measurements, J. Geophys. Res., 110, D14210, doi:10.1029/2005JD005882.

Sharma, S., D. Lavoué, H. Cachier, L. A. Barrie, and S. L. Gong (2004), Long-term trends of the black carbon concentrations in the Canadian Arctic, J. Geophys. Res., 109, D15203, doi:10.1029/2003JD004331.

Stanhill, G., and S. Cohen (2001), Global dimming: A review of evidence for a widespread and significant reduction in global radiation with discussion of its probable causes and possible agricultural consequences, Agric. For. Meteorol., 107, 255-278.

Tegen, I., P. Hollrig, M. Chin, I. Fung, D. Jacob, and J. Penner (1997), Contribution of different aerosol species to the global aerosol extinction optical thickness: Estimates from model results, J. Geophys. Res., 102(D20), 23,895-23,915.

Wielicki, B. A., and L. Parker (1992), On the determination of cloud cover from satellite sensors: The effect of sensor spatial resolution, J. Geophys. Res., 97(D12), 12,799-12,823.

Wild, M., H. Gilgen, A. Roesch, A. Ohmura, C. N. Long, E. G. Dutton, B. Forgan, A. Kallis, V. Russak, and A. Tsvetkov (2005), From dimming to brightening: Decadal changes in solar radiation at Earth's surface, Science, 308, 845-850

Zhang, Y., W. B. Rossow, A. A. Lacis, V. Oinas, and M. I. Mishchenko (2004), Calculation of radiative fluxes from the surface to top of atmosphere based on ISCCP and other global data sets: Refinements of the radiative transfer model and the input data, J. Geophys. Res., 109, D19105, doi:10.1029/2003JD004457.

S. Lohmann and R. Meyer, Institute of Atmospheric Physics, Deutsches Zentrum für Luft- und Raumfahrt, Oberpfaffenhofen, D-82234 Wessling, Germany. (sina.lohmann@stusta.de)

L. Riihimaki and F. Vignola, Solar Radiation Monitoring Lab, Department of Physics, University of Oregon, Eugene, OR 97403, USA. 